\title{
Students' Acceptance of Distance Learning as a Result of COVID- 19 Impact on Higher Education in Jordan
}

\author{
Yasmin Mohamad Hamdi Sakka (i) \\ Faculty of Administrative and Financial Sciences/Management, Information Systems Department, University of Petra, \\ Amman, Jordan \\ Correspondence should be addressed to Yasmin Mohamad Hamdi Sakka; ysakka@uop.edu.jo
}

Received 14 September 2021; Revised 15 January 2022; Accepted 17 January 2022; Published 23 February 2022

Academic Editor: Ehsan Namaziandost

Copyright @ 2022 Yasmin Mohamad Hamdi Sakka. This is an open access article distributed under the Creative Commons Attribution License, which permits unrestricted use, distribution, and reproduction in any medium, provided the original work is properly cited.

This study aimed to investigate determinants for student's acceptance of distance learning in Jordan at the time of COVID-19. This paper is dedicated to the higher education institutions shifting towards distance learning processes due to the global pandemic situation caused by COVID-19 in 2020. A conceptual framework was developed using a validated conceptual framework (UTAUT) that has proved its robustness in prior studies. The study made amendments for this framework as it excluded the actual use variable and was only concerned with the intention determinants, as online distance learning was imposed on students in higher education in Jordan, and there were no other available alternatives; therefore, the study investigates the drivers for intentions. This study also attempted to extend the theory, which does not underestimate the robustness and validity of the proposed framework. It was seen vital to cope with the consequences of the COVID-19 pandemic, which has become a strong influencer when considering the subject of this study. Two additional factors were suggested by the study, namely: perceived value and expected cost. The quantitative deductive exploratory methods, structural equation modelling, smart partial least squares (v.3.3), and path analysis was applied, which yielded interesting results.

\section{Introduction}

Countries have shifted away from traditional education in order to combat the spread of the new coronavirus disease (COVID-19). While multiple countries have historically faced various types of crises, distant education has not been employed to address them. Crisis distance education (CDE) is distinctive in its theory and practice, in several aspects distinguishing it from traditional distance education [1]. The first distinction is its abruptness. CDE was implemented in schools as a result of an unanticipated necessity, with no prior rules or planning [2]. The second distinction is internationalization. CDE has been employed as a non-pharmaceutical threat on a global scale, establishing a global fact and elevating learning to a global spectacle. Although it was historically an institutional issue, it is now a global concern [2].

1.1. Distance Learning. Numerous researchers have conducted extensive research on the impact of distance education on education and discovered that distance education has a number of benefits, including ensuring educational continuity $[3,4]$, promoting lifelong learning $[5,6]$, and lowering the high costs associated with traditional education [7]. As the teacher and the student were physically separated, limitations such as teaching techniques, scheduling, and time have remained $[8,9]$. Academic performance of students enrolled in hybrid programmes is consistently higher than that of those enrolled in just online programmes. In 2015, Kauffman [10] published a study on the elements affecting online learning and student achievement. In addition, Kauffman [10] adds that numerous research have demonstrated that online learning methods outperform face-to-face instruction. Numerous experts assert that it is difficult to make broad conclusions about the effectiveness of online learning, particularly given its major distinction from traditional education. Perhaps it is preferable to analyse certain issues more closely, such as the comparative merits and challenges of migrating to virtual learning, the conditions that must be in place to guarantee that it functions properly, and the way that learners with varying capacities experience this change. 
1.2. The UTAUT Model. Recently, several well-known theories and models have been used to describe the relationship between user expectations, behaviours, and behavioural intentions for the use of technology. Innovation diffusion theory (IDT), theory of reasoned action (TRA), theory of planned behaviour (TPB), social cognitive theory (SCT), motivational model (MM), model of PC utilisation (MPCU), technology acceptance model (TAM), and a hybrid model that blends TAM and TPB frameworks are only a few of the key modular methods that lead the way. The unified theory of acceptance and use of technology (UTAUT) was developed to analyse and combine these eight models of technology [11]. This model helps to identify users' intentions to use information technology system and their subsequent behaviour.

The model holds four main constructs: performance expectancy, effort expectancy, social influence, and facilitating conditions. Owing to its simplicity and robustness, this model is considered one of the most commonly used ones $[12,13]$. A study based on the UTAUT model conducted in Indonesia indicated that performance expectancy, effort expectancy, and social influence were found not to be influenced by age and gender [14]. Results of the study "Assessing User Acceptance toward Blog Technology Using the UTAUT Model" examined and indicated that distance learning could attract and sustain the interest and attention of students. The study explained that social influence proved to be a powerful booster for students to use blogs in the process of distance learning [14]. Different leading studies have indicated that performance expectancy explained a substantial positive impact on behavioural intention and one of the best predictors to explain behavioural intention relationship [15].

A study titled "A Model of ICT Acceptance and Use for Teachers in Higher Education Institutions" indicated that all four UTAUT model constructs were found to be a good behavioural intention predictor, while performance expectancy was found to be the most influential one among teachers for the adoption and use of ICT [16]. It is difficult to take online lessons without first obtaining a high-speed Internet connection and purchasing a laptop/desktop or other smart device. Students will pay a price for this. As a result, the anticipated cost was examined. Numerous evaluations of case studies demonstrate that integrating distance learning into face-to-face courses can have a significant impact on learning outcomes [17]. According to Obeidat's study “Undergraduate Students' Perspective on Online Learning: A Case Study of Hashemite University Students," students agree that e-learning is critical for facilitating and developing their university learning experience. However, a blend of face-to-face instruction and online activities (discussion boards and short answer quizzes) is still necessary. It was believed that e-learning should occasionally be utilised in lieu of face-to-face instruction.

1.3. Jordanian Higher Education Policy. COVID-19 has dramatically reshaped the way global higher education is being delivered. As a result, universities are increasingly changing how they collaborate and work to meet students and employees' emerging needs. In Jordan, using various programs and implementations, all universities have shifted to distance learning. The Jordanian Ministry of Higher Education and Scientific Research has asked universities to take appropriate steps to deal with the pandemic, in March 2020, since the beginning of the pandemic, from distributing numerous instructional leaflets produced by the Ministry of Health to the highest possible number of students and members of the teaching and administrative staff, along with the availability of sterile materials of various kinds in all university facilities.

The Ministry did not stop but instead expanded the request from universities to set up an emergency plan and form an emergency committee to apply and amend this plan's provisions. The Ministry also asked universities to inform international students not to travel to their countries, especially those where the coronavirus has spread, in anticipation of the possibility that they will not be allowed to return to Jordan due to the possibility of a decision to close the land, sea, and airports. Universities were also asked to take appropriate measures to move to distance learning, starting with providing the necessary application and each faculty member preparing lectures for the next two weeks so that the courses could be downloaded electronically.

With the continuation of the corona crisis locally and internationally, a new set of higher education council decisions related to organising the study process in Jordanian universities during the coronavirus crisis, which were taken in consultation with the heads of public and private universities, included: directing Jordanian universities, colleges, and intermediate university colleges to do the following regarding undergraduate and intermediate diploma students in various disciplines (except for medicine and dentistry majors). The decisions of the higher education council granted by the defense law included the powers to arrange the details of the examinations and the course of the educational and teaching process, as it was determined that the final exam would be conducted. A percentage (50\%-70\%) of the final mark was allocated to it. The rest of the marks were distributed on short exams, reports, duties, and participation through E-learning and any examinations held before the study suspension period. Announcing the date of the final exam for students within a period of not less than a week from the date of returning to teaching on campus. After monitoring the final mark of the student in each course, the student is informed of his outcome in each course. The student may choose to monitor the result (pass/fail) of the course within a week at most from the date of announcing the results by submitting a written request to the deanship/ unit/department of admission and registration at the university. Otherwise, the student is given his final mark according to the system used (percentage mark or letter).

The results of the Ministry of Higher Education's meeting, which was held using remote communication technology with the presidents of official universities, were also circulated, which relates to the necessity of developing electronic content for academic courses, following up on the 
training of faculty members, making announcements to students using electronic platforms, and choosing the best electronic content for the people. Multiple students from the same academic course and circulating it to all people, considering the accuracy and objectivity of the number of electronically loaded courses and the number of students who are announced to avoid raising the level of expectations in a way that does not match the actual reality.

\section{Theoretical Background and Hypotheses}

The proposed research model is represented in Figure 1, and a detailed description of each variable is described in the next subsections. This study employs a quantitative research approach to test the proposed research model. A personally administered questionnaire was used to collect data from a convenient sample from university students in Jordan.

\subsection{Performance Expectancy. Performance expectancy} measures the degree to which an individual believes that using a distance learning system will help him/her perform learning tasks. Performance expectancy of technologies (in this case, tools applied for university distance learning during the pandemic) is essential in the model. Performance expectancy is understood as the degree to which a user of a particular system believes that it would improve his/her work or study performance compared to alternative methods of carrying out the user's tasks [18]. In the context of distance learning, to which universities have had to switch because of the pandemic, the authors have used the research model to formulate the following hypotheses about performance expectancy:

$H_{1}$ : performance expectancy of distance learning positively affects students' intention to use distance learning systems.

2.2. Effort Expectancy. When users' perceptions of the ease of use and the technology's usefulness are positive, they will embrace new technology without any problem [19].

$\mathrm{H}_{2}$ : effort expectancy of use of distance learning systems positively affects students' intention towards using distance learning tools.

2.3. Social Influence. Social influence refers to the social pressure coming from the external environment that surrounds the individuals and may affect their perceptions and behaviors of engaging in a particular action, such as friends, relatives, and superiors [20].

$\mathrm{H}_{3}$ : social influence of use of distance learning systems positively affects students' intention towards using distance learning tools.

\subsection{Expected cost}

$\mathrm{H}_{4}$ : expected cost of use of distance learning systems positively affects students' intention towards using distance learning tools.

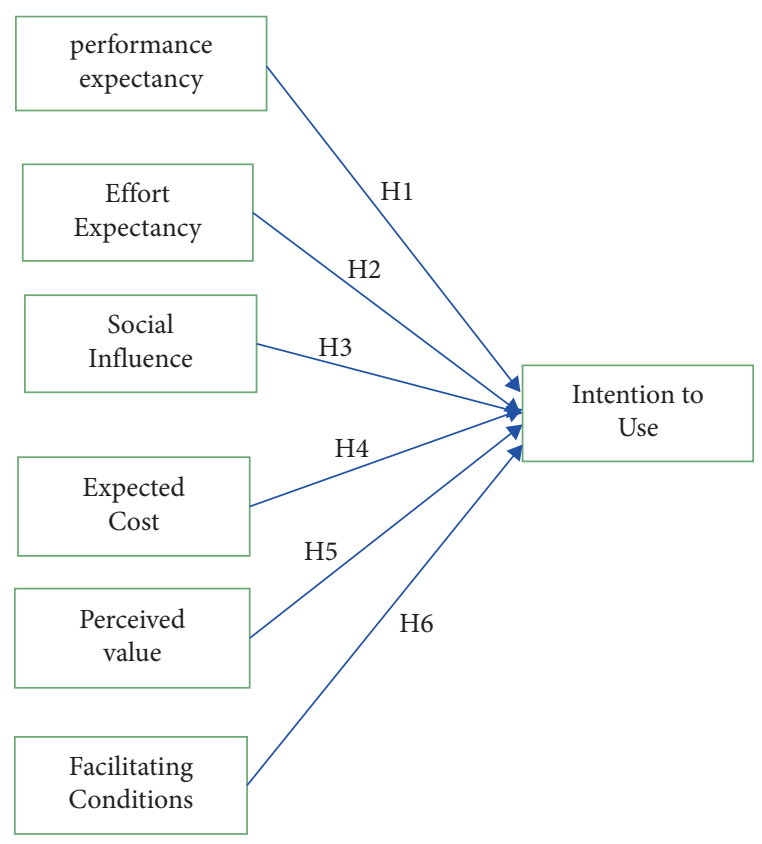

Figure 1: Research model.

\subsection{Perceived Value}

$H_{5}$ : perceived value of use of distance learning systems positively affects students' intention towards using distance learning tools.

\subsection{Facilitating Conditions}

$\mathrm{H}_{6}$ : facilitating conditions positively affects the actual use of distance learning systems by students.

2.7. Intention to Use. It is considered that the user's intention to use technology affects his/her decision on whether to use it (actual use). TAM adaptation for examining students' satisfaction and technology adoption in online classes allowed for finding out that students' intention to use technology influences their learning outcomes in the online class environment [21]. All these facts allowed the authors to formulate the following hypothesis.

\section{Research Methodology}

To achieve the goal of this study, the quantitative deductive exploratory methods were used, considering that this study aims to investigate determinants for student's acceptance of distance learning in Jordan at the time of COVID-19. Accordingly, the quantitative method provided the source of primary data that gathered students' perceptions using a self-administered questionnaire, whereas the deductive exploratory methods explained the relationships between the proposed factors and student intention. The study was crosssectional, considering that students perceptions were gathered at one point of time. To complete statistical analysis, data were coded into SPSS (version 26). Data 
screening was completed, along with conducting preliminary analysis to confirm data reliability. In contrast, structural equation modelling (SEM) was used through smart partial least squares (version 3.3) to validate the measurement model and complete path analysis to gather path estimates for significant determinants for intentions.

PLS seemed appropriate for this study, considering this approach allowed for testing many constructs that are included in complex models, along with structural testing paths with neglecting distribution assumptions related to data [22]. Moreover, when considering the small sample size in this study, PLS provides stronger levels of statistical power because this approach makes use of an algorithm that computes the relationships of the measurement model and structural model separately, not simultaneously $[22,23]$.

3.1. Instrument Design and Scales. This study made use of a validated conceptual framework (UTAUT) that has proved its robustness in prior studies; [11] therefore, the instrument made use of a pretested scale that has confirmed its statistical reliability and validity in many studies; however, the study made amendments for this framework as it excluded the actual use variable and only considered the intention determinates, as online distance learning was imposed on students in higher education in Jordan and thus made no other available alternatives; therefore, the study investigated the drivers for intentions; accordingly, the hypothesis related to facilitating conditions was modified to influences intention.

This study also provided an attempt to extend the theory, and this does not underestimate the robustness and validity of the proposed framework. This was seen as vital to cope with the consequences of the pandemic, which has become a strong influencer when considering the subject of this study, so two additional factors were suggested by the study, namely: perceived value and expected cost. In total, the instrument included [21] statements that measured the factors of the proposed model as follows: three items for performance expectancy, and statements were adopted from the study of Joo et al. [21]; four items for effort expectancy, and statements were adopted from the study of Nahla Aljojo [24]; three items for social influence, and statements were adopted from the study of Tarhini et al. [25]; four items for facilitating conditions, and statements were adopted from the study of Isaias et al. [26]; three items for expected cost, and statements were adopted from the study of Sedlock [27]; three items for intention to use, and statements were adopted from the study of Abbas [28]; and five items for perceived value, and statements were adopted from the study of Radhakrishnan [29]. All statements were anchored to the Likert-type scale, which provides five levels of agreement that were coded as follows $(5 \longrightarrow$ strongly agree, $4 \longrightarrow$ agree, $3 \longrightarrow$ neutral, $2 \longrightarrow$ disagree, and $1 \longrightarrow$ strongly disagree). The demographic section gathered data related to student education that included university to ensure that participant was a college student to provide that the sample comprised of students from different colleges denoting that the views of students of both science and humanities faculties were included in the sample. Moreover, students were asked to determine if he/she is working along with studying as the study was concerned with distance learning; therefore, it was believed that distance learning might provide a solution for students who work, and accordingly, it was expected that they would have a higher level of intentions to enrol in distance learning; finally, the studying year was also collected to ensure that the study has students who have completed different years to capture the views of the majority of students. After completing the instrument, it was handed over to the experts who were asked to validate the instrument's content and, after receiving it, made few adjustments. Then, a language editor proofread it for language reliability and suitability, and finally, Google form was selected as the medium for the instrument.

3.2. Context and Sampling. This study was conducted in the context of higher education due to scarce data in this regard in Jordan at the time of COVID-19 that made distance learning compulsory; therefore, despite that distance learning was imposed with no other option, the study is still concerned with the students' intentions, whether they acutely have high level of intention to enrol in distance learning or not despite they acutely use it. This was the concern because the aim was to provide deep understanding whether distance learning is perceived by students as acutely providing better performance, require less efforts, and so on. Therefore, higher education students were targeted in this study. The focus was on students as they are the actual players who are fundamentally affected by this process and the most capable ones for identifying the motives and reasons that may drive or hinder them to enrol in distance learning if they have an option of not to enrol. The study focused on students at private universities at Capital Amman, Jordan, considering these universities allocate significant budget and various means to provide its best in the field of distance learning. All students in the private universities of Amman were targeted, who make a large population; however, an exact or approximate number of those students could not be provided because of COVID-19, which imposed working remotely, and therefore, it was not possible to communicate through official channels with each university to obtain the exact number. Moreover, due to COVID-19, many students postponed semesters, in addition to that many students stayed outside the country because of restriction imposed on travel, and consequently, the total number of targeted population cannot be obtained; therefore, the online questionnaire was used, and the link was sent through the official e-mail at universities to students who responded to the researcher; moreover, social media platforms, such as Facebook and WhatsApp groups, were used to reach the students. Data collection started in August, 2020, and completed at December, 2020. Accordingly, the nonprobability convenience sampling was used because this 
method allowed to include participants who are close to hand [30].

3.3. Data Screening and Preliminary Analysis. In total, the questionnaire collected 178 responses; data screening was conducted, and all responses were valid, as STD value for each participant responses was gathered and scored high values denoting no patterns in answers. Moreover, four statements were formulated as reverse statements to capture any unengaged responses, and after reversing responses, no unengaged responses were seen: accordingly, a total of 178 responses were deemed for further analysis.

\section{Results}

4.1. Sample Profile and Descriptive Analysis. Table 1 displayed sample profile, and the summary of participants can be described as follow: the sample comprised of participants from both science and humanities faculties: department of administrative and financial sciences $(N=102,57.3 \%)$, medicine department $(N=7,3.9 \%)$, dentistry department $(N=6,3.4 \%)$, pharmacy department $(N=19,10.7 \%)$, engineering department $(N=21,11.8 \%)$, IT $(N=4,2.2 \%)$, faculty of arts $(N=1,6.2 \%)$, faculty of educational sciences $(N=2,1.1 \%)$, college of veterinary medicine $(N=1,0.6 \%)$, faculty of agriculture $(N=1,0.6 \%)$, faculty of law $(N=1$, $0.6 \%)$, and college of allied medical sciences $(N=3,1.7)$. The sample also included participants from different academic years as follows: first year $(N=10,5.6 \%)$, second year $(N=32,18.0 \%)$, third year $(N=61,34.3 \%)$, fourth year $(N=61,34.3 \%)$, and more than 4 year $(N=14,7.9 \%)$. Finally, more than half of the students reported that they are not working while studying $(N=112,62.9 \%)$, whereas $(N=65,36.5 \%)$ reported that they work and study.

In viewing STD values, it was seen that responses were not clustered around the mean for all factors except for social influence and expected cost, denoting no consensus in respondents' perceptions (Table 2). Descriptive analysis was provided in Table 3 using mean, STD, and Pearson's correlations, and the scale suggested by Sekaran and Bougie [30] was used to rank mean levels. All proposed factors and intention scored moderate level of agreement, as mean values scored as follows: performance expectancy (mean$=2.85)$, effort expectancy (mean $=3.09)$, social influence $($ mean $=3.11)$, expected cost $($ mean $=3.15)$, perceived value $($ mean $=2.60)$, facilitating conditions $($ mean $=3.15)$, and intention $($ mean $=2.88)$, these values provide initial indicators the respondents perceived that distance learning provide better performance to moderate level and require moderate level of effort; moreover, students influenced by their colleagues to moderate level and perceive that distance learning cost them to moderate level, and they perceived that they will gain value to moderate level, whereas they have all facilitating conditions to moderate level, and finally they have moderate level of intention toward using distance learning, indeed these indicators denote that students do not perceive distance learning as optimal solution.

Referring to Pearson's correlations, it was seen that all proposed determinants correlated to each other significantly to moderate level as the least value of correlation scored $\left(r=0.276^{* *}\right)$, whereas the highest level of correlation scored $\left(r=0.786^{* *}\right)$, evidently far below $(r=0.90)$ denoting no issue of multicollinearity. All determinants correlated significantly with intention, and the strongest correlation was with perceived value, remaining correlation were seen in moderate level as follows: performance expectancy $\left(r=0.617^{* *}\right)$, effort expectancy $\left(r=0.518^{* *}\right)$, social influence $\left(r=0.542^{* *}\right)$, expected cost $\left(r=0.327^{* *}\right)$, perceived value $\left(r=0.770^{* *}\right)$, and facilitating conditions $\left(r=0.445^{* *}\right)$. Finally, the values of tolerance and variance inflation factor were gathered, and VIF scored 1.779, 2.015, 1.539, 2.243, 1.673, and 3.079, whereas tolerance values exceeded (0.05) in line with suggestions and confirming that data have no issue of multicollinearity.

4.2. Statistical Analysis and General Findings. This section presented results using SEM-PLS. SEM analysis was conducted in two steps. Step 1: assess the measurement model, and Step 2: test the structural model to examine path values.

4.3. Measurement Model. In this step, all measures were entered into the measurement model to test for reliability and validity aspects before proceeding with testing structural model. Statements with loading values less than 0.50 were dropped from the model in line with suggestions of Hair et al. [31]. Statement effort (4) and facilitating conditions (1) and (4) were dropped from the model, and all remaining statements scored high values of loading exceeding minimum standard (0.50). Scales were tested for convergent validity that was prevailed considering that majority of statements scored high values of loading and achieved significance as ( $T$-statistics) exceeded (1.96), moreover, average variance extracted exceeded $(0.50)$ for all factors except for excepted cost that was seen approximately reaching the minimum required value. The value of AVE scored as follows: performance expectancy (0.696), effort expectancy $(0.802)$, social influence $(0.631)$, expected cost (0.466), perceived value (0.763), facilitating conditions (0.825), and intention (0.633). Moreover, Rho_A values also exceeded 0.70 in line with suggestions of Hair et al. [31], values scored as follows: performance expectancy (0.811), effort expectancy (0.890), social influence (0.711), expected cost $(0.612)$, perceived value $(0.923)$, facilitating conditions (0.792), and intention (0.753).

In relation to internal consistency, values of composite reliability (CR) and Cronbach's $\alpha$ were gathered, and the values of both criterions should exceed threshold of 0.70 , and this was confirmed for all factors expect for expected cost again, denoting this factor was seen barely to confirm the requirements of validity and reliability, and this provided a limitation in this study that future studies need to consider by adopting or extending the measure. Values of Cronbach's 
TABLe 1: Sample profile $(N=178)$.

\begin{tabular}{|c|c|c|c|}
\hline & Category & Count & $\%$ \\
\hline \multirow{13}{*}{ College } & Department of administrative and financial sciences & 102 & 57.3 \\
\hline & Medicine department & 7 & 3.9 \\
\hline & Dentistry department & 6 & 3.4 \\
\hline & Pharmacy department & 19 & 10.7 \\
\hline & Engineering department & 21 & 11.8 \\
\hline & IT & 4 & 2.2 \\
\hline & Faculty of arts & 11 & 6.2 \\
\hline & Faculty of educational sciences & 2 & 1.1 \\
\hline & College of veterinary medicine & 1 & 0.6 \\
\hline & Faculty of agriculture & 1 & 0.6 \\
\hline & Faculty of low & 1 & 0.6 \\
\hline & College of allied medical sciences & 3 & 1.7 \\
\hline & Total & 178 & 100 \\
\hline \multirow{6}{*}{ Academic year } & First year & 10 & 5.6 \\
\hline & Second year & 32 & 18.0 \\
\hline & Third year & 61 & 34.3 \\
\hline & Fourth year & 61 & 34.3 \\
\hline & More than 4 year & 14 & 7.9 \\
\hline & Total & 178 & 100.0 \\
\hline \multirow{4}{*}{ Work and studying } & Yes & 65 & 36.5 \\
\hline & No & 112 & 62.9 \\
\hline & Missing & 1 & 0.6 \\
\hline & Total & 178 & 100.0 \\
\hline
\end{tabular}

TABLE 2: Mean and SD values and its interpretation.

\begin{tabular}{lccc}
\hline & Mean & SD & Dange \\
Range & Agreement level & Less than 1 & Clustered around the mean \\
$1-2.339$ & Low agreement & Moderate agreement & Clustered away from the mean \\
$3.34-3.669$ & High critical & More than 1 & \\
\hline
\end{tabular}

TABle 3: Descriptive analysis.

\begin{tabular}{|c|c|c|c|c|c|c|c|c|c|c|}
\hline \multirow{2}{*}{$N=178$} & \multirow{2}{*}{ Mean } & \multirow{2}{*}{ Level } & \multirow{2}{*}{ SD } & \multicolumn{7}{|c|}{ Correlation } \\
\hline & & & & 1 & 2 & 3 & 4 & 5 & 6 & 7 \\
\hline $\mathrm{PE}$ & 2.85 & Moderate & 1.07 & 1 & & & & & & \\
\hline $\mathrm{EE}$ & 3.09 & Moderate & 1.00 & $0.610^{* *}$ & 1 & & & & & \\
\hline SI & 3.11 & Moderate & 0.93 & $0.636^{* *}$ & $0.477^{* *}$ & 1 & & & & \\
\hline EC & 3.15 & Moderate & 0.93 & $0.367^{* *}$ & $0.516^{* *}$ & $0.276^{* *}$ & 1 & & & \\
\hline PV & 2.60 & Moderate & 1.10 & $0.786^{* *}$ & $0.587^{* *}$ & $0.639^{* *}$ & $0.473^{* *}$ & 1 & & \\
\hline FC & 3.15 & Moderate & 0.79 & $0.517^{* *}$ & $0.410^{* *}$ & $0.566^{* *}$ & $0.406^{* *}$ & $0.527^{* *}$ & 1 & \\
\hline Intention & 2.88 & Moderate & 1.06 & $0.617^{* *}$ & $0.518^{* *}$ & $0.542^{* *}$ & $0.327^{* *}$ & $0.770^{* *}$ & $0.445^{* *}$ & 1 \\
\hline
\end{tabular}

${ }^{* *}$ Correlation is significant at $(0.01)$.

$\alpha / \mathrm{CR}$ scored as follows: performance expectancy (0.784/ $0.696)$, effort expectancy $(0.878 / 0.802)$, social influence $(0.710 / 0.837)$, expected cost $(0.566 / 0.466)$, perceived value $(0.922 / 0.763)$, facilitating conditions $(0.788 / 0.825)$, and intention $(0.715 / 0.633)$. Statistical validity and reliability of the measurement model were prevailed; hence, it is suitable to proceed with testing the structural model. Table 4 displayed statistical reliability and validity of the model.

4.4. Structural Model. After establishing statistical validity and reliability of the model, path analysis was applied to examine the linear regression influence of the proposed factors on intention in an effort to identify the patterns of the relationships between the proposed constructs. The structural model was assessed by gathering values of explained variance $\left(R^{2}\right)$, path coefficient $(\beta)$, and path significance $(p$ value) in line with directions of Hair et al. [31]. Path analysis reported that the proposed factors scored an explained variance $\left(R^{2}=62.5 \%\right)$, denoting that the proposed factors explained moderate level of variance in student intentions, this also denoted that there are other factors that still play significant role in shaping student intentions toward adopting distance learning. 
TABLE 4: Statistical reliability and validity $(N=178)$.

\begin{tabular}{|c|c|c|c|c|c|c|}
\hline Factor & Code & AVE & Rho_A & Cronbach $\alpha /$ CR & Loading & Value of $T$ \\
\hline \multirow{3}{*}{ Performance expectancy } & Performance_1 & \multirow{3}{*}{0.696} & \multirow{3}{*}{0.811} & \multirow{3}{*}{$0.784 / 0.696$} & 0.885 & $39.793^{* * *}$ \\
\hline & Performance_2 & & & & 0.769 & $19.382^{* *}$ \\
\hline & Performance_3 & & & & 0.844 & $32.998^{* * *}$ \\
\hline \multirow{3}{*}{ Effort expectancy } & Effort_1 & \multirow{3}{*}{0.802} & \multirow{3}{*}{0.890} & \multirow{3}{*}{$0.878 / 0.802$} & 0.901 & $50.306^{* * *}$ \\
\hline & Effort_2 & & & & 0.898 & $55.533^{* * *}$ \\
\hline & Effort_3 & & & & 0.887 & $36.519^{* * *}$ \\
\hline \multirow{3}{*}{ Social influence } & Social_1 & \multirow{3}{*}{0.631} & \multirow{3}{*}{0.711} & \multirow{3}{*}{$0.710 / 0.837$} & 0.785 & $19.085^{* * *}$ \\
\hline & Social_2 & & & & 0.819 & $22.196^{* * *}$ \\
\hline & Social_3 & & & & 0.779 & $16.592^{* * *}$ \\
\hline \multirow{3}{*}{ Expected cost } & Cost_1 & \multirow{3}{*}{0.466} & \multirow{3}{*}{0.612} & \multirow{3}{*}{$0.566 / 0.466$} & 0.539 & $2.416^{* * *}$ \\
\hline & Cost_2 & & & & 0.607 & $2.692^{* * *}$ \\
\hline & Cost_3 & & & & 0.860 & $9.875^{* * *}$ \\
\hline \multirow{5}{*}{ Perceived value } & Value_1 & \multirow{5}{*}{0.763} & \multirow{5}{*}{0.923} & \multirow{5}{*}{$0.922 / 0.763$} & 0.897 & $50.708^{* * *}$ \\
\hline & Value_2 & & & & 0.840 & $32.121^{* * *}$ \\
\hline & Value_3 & & & & 0.881 & $43.603^{* * *}$ \\
\hline & Value_4 & & & & 0.896 & $54.065^{* * *}$ \\
\hline & Value_5 & & & & 0.852 & $32.556^{* * *}$ \\
\hline \multirow{2}{*}{ Facilitating conditions } & Facilitating_1 & \multirow{2}{*}{0.825} & \multirow{2}{*}{0.792} & \multirow{2}{*}{$0.788 / 0.825$} & 0.900 & $41.018^{* * *}$ \\
\hline & Facilitating_2 & & & & 0.917 & $38.296^{* * *}$ \\
\hline \multirow{3}{*}{ Intention } & Intention_1 & \multirow{3}{*}{0.633} & \multirow{3}{*}{0.753} & \multirow{3}{*}{$0.715 / 0.633$} & 0.796 & $28.349^{* * *}$ \\
\hline & Intention_2 & & & & 0.757 & $13.813^{* * *}$ \\
\hline & Intention_3 & & & & 0.833 & $39.514^{* * *}$ \\
\hline
\end{tabular}

${ }^{* * *}$ Significant at $(0.05)$ level.

Results reported that all proposed factors were insignificant except perceived value that scored significantly positive and strong influence considering that path estimate scored $(\beta=0.709, p=0.000)$, hence providing support for the proposed hypothesis $\left(H_{5}\right)$ : Perceived value of using distance learning systems positively affects students' intention towards using distance learning tools.

Path estimate for performance expectancy factor scored $(\beta=-0.025, p=0.808)$, render no support for the proposed hypothesis $\left(H_{1}\right)$ : Performance expectancy of using distance learning systems positively affects students' intention towards using distance learning tools. For effort expectancy path estimate scored $(\beta=0.104, p=0.191)$ also render no support for $\left(\mathrm{H}_{2}\right)$ : Effort expectancy of using distance learning systems positively affects students' intention towards using distance learning tools. Path estimate for social influence scored $(\beta=0.063, p=0.377)$, providing no support for $\left(\mathrm{H}_{3}\right)$ : Social influence of using distance learning systems positively affects students' intention towards using distance learning tools. Th path estimate for expected cost scored $(\beta=0.021, p=0.0776)$ rejecting $\left(H_{4}\right)$ : Expected cost of using distance learning systems positively affects students' intention towards using distance learning tools. Finally, path value for the final hypothesis was also not supported considering that $(\beta=-0.035, p=0.581)\left(H_{6}\right)$ : Facilitating conditions to use distance learning systems positively affects students' intention towards using distance learning tools. Table 5 displayed a summary of path estimates and hypotheses decision, whereas Figure 2 presented structural model testing.

Finally, as the study collected in the demographic section a dichotomy variable whether the student work in time of studying. The study aimed to examine if students who work prefer distance learning more than students who do not work, as it makes sense that students who work may perceive distance learning as time saving as it allows them to work. For this purpose, the study established a multigroup analysis (MGA), to compare path estimates for students who work with students who do not. Path estimates reported that all factors were still insignificant for the two groups except for perceived value path which was significant for the two groups, this was also supported in the results of the parametric test for comparing two groups as $p$ values for all paths difference were insignificant as scored as follow: performance expectancy $(\beta=-0.318, p=0.138)$, effort expectancy $(\beta=0.009, p=0.964)$, social influence $(\beta=0.031, p=0.841)$, expected cost $(\beta=-0.181, p=0.320)$, perceived value $(\beta=0.210, p=0.243)$, and facilitating conditions $(\beta=0.100$, $p=0.434)$. This evidently denoted that students regardless working or not have the same perceptions toward determinants of distance learning intention.

\section{Discussion}

The purpose of this study was to determine the factors that influence students' acceptance of distant learning in Jordan during COVID-19. The study used a validated conceptual framework (UTAUT) that has been shown to be robust in prior research and amended it to exclude the actual use variable and focus exclusively on intention determinants. As online distance learning was imposed on students in Jordan's higher education system, leaving no other available alternatives, the study focused on intention drivers. 
TABLE 5: Summary of path estimates.

\begin{tabular}{lcccc}
\hline Hypothesis & Path & $\beta$ & $p$ & Decision \\
\hline$H_{1}$ & Performance expectancy $\longrightarrow$ intention & -0.025 & 0.808 & Not supported \\
$H_{2}$ & Effort expectancy $\longrightarrow$ intention & 0.104 & 0.191 & Not supported \\
$H_{3}$ & Social influence $\longrightarrow$ intention & 0.063 & 0.377 & Not supported \\
$H_{4}$ & Expected cost $\longrightarrow$ intention & 0.021 & 0.776 & Not supported \\
$H_{5}$ & Perceived value $\longrightarrow$ intention & 0.709 & 0.000 & Supported \\
$H_{6}$ & Facilitating conditions $\longrightarrow$ intention & -0.035 & 0.581 & Not supported \\
\hline
\end{tabular}

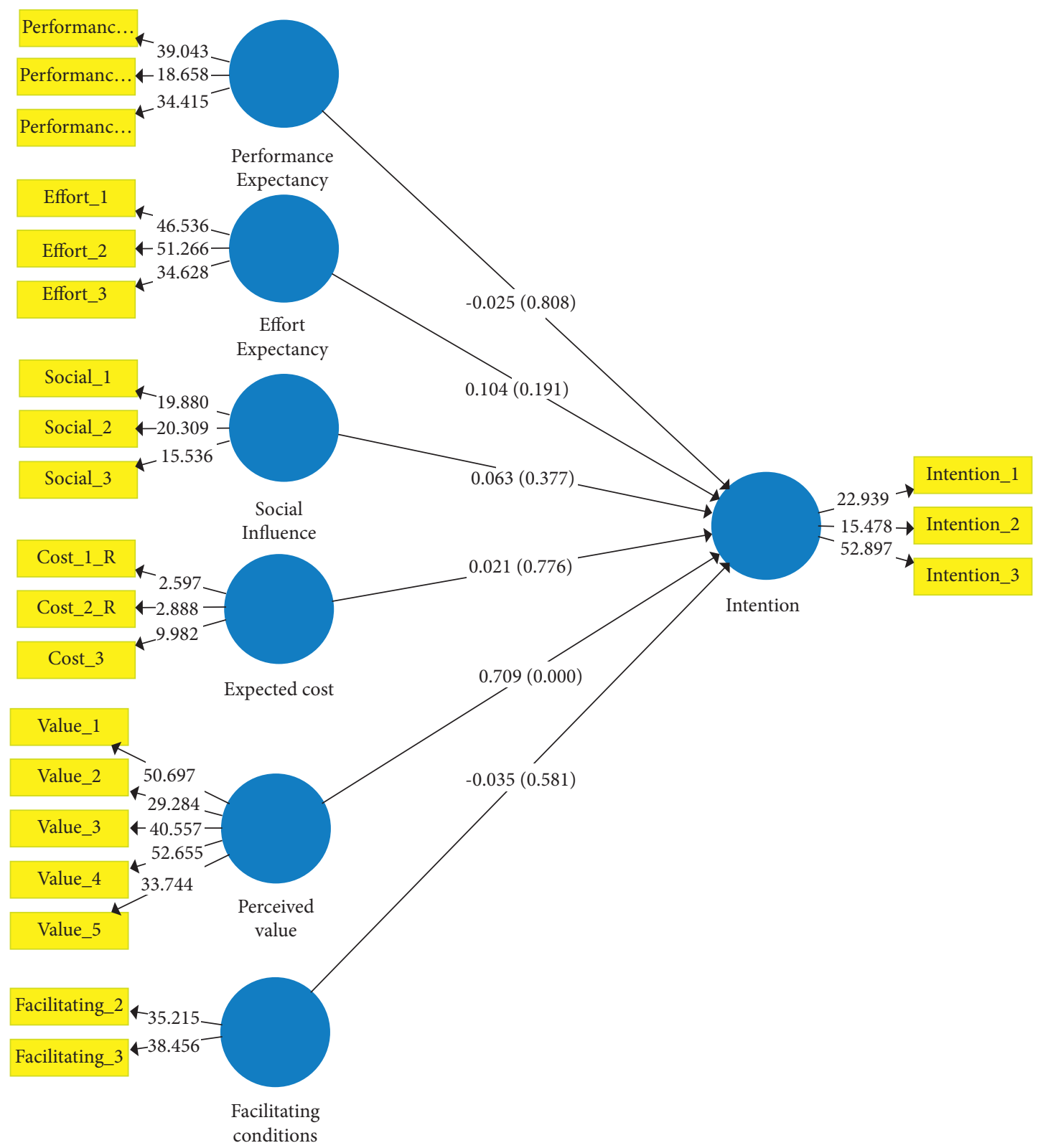

Figure 2: Structural model testing.

This study also attempted to extend the theory, which does not diminish the robustness or validity of the proposed framework; this was deemed necessary in order to deal with the consequences of the pandemic, which has become a strong influencer when considering the subject of this study; thus, two additional factors were suggested, namely: perceived value and expected cost. The proposed factors explained a moderate amount of variance in student intentions $\left(R^{2}=62.5 \%\right)$, indicating that additional factors continue to play a significant role in determining student intentions toward remote learning adoption. 
Students exhibited a preference for face-to-face instruction and reported higher levels of cognitive engagement, learning, and comprehension related with this mode of instruction. Significant disparities in students' responses were noted according to their year of study. In general, students in their first years of study appear to view the current state of remote teaching as more unsatisfactory than more senior students [32]. Results also contribute to the robustness of UTAUT model, as the proposed factors were able to explain moderate level of variance in intentions; however, when viewing path estimates results, critical indicators were seen. All proposed factors were insignificant except one factor that were incorporated by the researcher; indeed, this do not underestimate the value of UTAUT model, this indeed related to the time of conducting the study and the topic being investigated.

This study is concerned with distance learning system which can be seen as any other information system that can be investigated through UTAUT. The UTAUT model has been reported to be robust and trustworthy for use on a variety of technologies, as well as viable following any modification operation. In addition, due to the minimal number of constructs and moderating variables, it is more practical and clear for studying the acceptance behavior of any new technology [11]. However, given that the transition to this system occurred abruptly as a result of the pandemic's conditions, these findings reflect a lack of readiness on the part of both students and universities to use these systems, indicating the presence of a significant flaw in Jordan experience with distance learning for higher education. Students from remote and impoverished locations faced numerous obstacles, including limited technical access, inadequate Internet connectivity, and hostile study conditions. In addition, this study emphasises the importance of electronic commerce in altering distance education [33]. Indeed, it is evident that distance learning systems contribute to reducing the effort required of students, but this was not sufficient motivation for students in Jordan to increase their intentions toward adopting these systems, and it was also noted that, while these systems do reduce the effort required of students to complete the process, they were also ineffective in this study, which may be an indication of students' lack of motivation.

Social influence was not a significant driver, which can be explained by the pandemic's compulsory use, as regardless of whether significant people to students believe they should use distance learning or not, this was not enough to increase their intentions. In addition, facilitating conditions were not a significant driver and scored negatively, which clearly represents technological, supporting, training, and communication barriers that impede students' intentions. In contrast to our findings, a study from Bangladesh concluded that positive influence from instructors and mentors may help increase acceptance of e-learning, as "social influence" was validated as a major predictor of the variables: intention to behave in a certain way and perceived usefulness [34]. Concerning the study's proposed factors, the absence of expected cost indicates that financial barriers may exist, and thus decision makers should consider the availability of various requirements for students. This can be accomplished by providing students with Internet subscriptions that enable distance learning communication, laboratories, and computers, as financial ability varies among students.

When it comes to perceived value influence, it is clear that this driver was dominating, and it is critical to remember that the researcher proposed it, as this driver enabled the researcher to align and establish the model for distant learning. As students were transited to use the system, they used it to fulfil semester requirements, which mostly focused on acquiring a greater understanding of the courses.

\section{Conclusion}

The findings provided critical indicators for decision makers; they should consider that in the case of Jordanian students, their primary motivation for using distance learning is the value they can achieve, regardless of expected performance, cost, or effort, and thus distance learning and traditional learning are equivalent. The study discovered that students were unaware of the benefits of distant learning, such as reduced effort and improved performance. Decision makers should take these findings into account and focus their efforts on increasing students' awareness of the benefits of distance learning and how it can benefit them not only in terms of completing courses but also in terms of achieving a variety of goals, such as saving time and money on transportation costs to attend lectures in person. Future research examining the influence of distant education on students is required in multicentre settings with a high sample size.

\section{Data Availability}

The data will be available for review from the corresponding author on request.

\section{Conflicts of Interest}

The authors declare no conflicts of interest.

\section{Acknowledgments}

The author is thankful to all the associated personnel who contributed to this study by any means.

\section{References}

[1] A. E. Al Lily, A. F. Ismail, F. M. Abunasser, and R. H. Alhajhoj Alqahtani, "Distance education as a response to pandemics: coronavirus and Arab culture," Technology in Society, vol. 63, Article ID 101317, 2020.

[2] A. Bozkurt, I. Jung, J. Xiao et al., "A global outlook to the interruption of education due to COVID-19 pandemic: navigating in a time of uncertainty and crisis," Asian Journal of Distance Education, vol. 15, pp. 1-126, 2020.

[3] B. O. Akinbadewa and O. A. Sofowora, "The effectiveness of multimedia instructional learning packages in enhancing secondary school students' attitudes toward biology," International Journal on Studies in Education, vol. 2, no. 2, pp. 119-133, 2020. 
[4] S. J. Seage and M. Türegün, "The effects of blended learning on STEM achievement of elementary school students," International Journal of Educational Research, vol. 6, pp. 133-140, 2020.

[5] M. Alharthi, "Students' attitudes toward the use of technology in online courses," International Journal of Technology in Education, vol. 3, pp. 14-23, 2020.

[6] D. Serhan, "Web-based homework systems: students' perceptions of course interaction and learning in mathematics," International Journal on Social and Education Sciences, vol. 1, no. 2, pp. 57-62, 2019.

[7] N. A. Al-Husban, "Critical thinking skills in asynchronous discussion forums: a case study," International Journal of Technology in Education, vol. 3, no. 2, pp. 82-91, 2020.

[8] V. L. Thompson and Y. L. McDowell, "A case study comparing student experiences and success in an undergraduate course offered through online, blended, and face-to-face instruction," International Journal of Education in Mathematics, Science and Technology, vol. 7, pp. 116-136, 2019.

[9] R. Weinhandl, Z. Lavicza, M. Hohenwarter, and S. Schallert, "Enhancing flipped mathematics education by utilising GeoGebra," International Journal of Education in Mathematics, Science and Technology, vol. 8, no. 1, pp. 1-15, 2020.

[10] H. Kauffman, "A review of predictive factors of student success in and satisfaction with online learning," Research in Learning Technology, vol. 23, 2015.

[11] A. M. Momani, "The unified theory of acceptance and use of technology," International Journal of Sociotechnology and Knowledge Development, vol. 12, no. 3, pp. 79-98, 2020.

[12] A. Tarhini, M. Hassouna, M. S. Abbasi, and J. Orozco, "Towards the acceptance of RSS to support learning: an empirical study to validate the technology acceptance model in Lebanon," Electronic Journal of e-Learning, vol. 13, pp. 30-41, 2015.

[13] Y. Y. Yuen, P. Yeow, N. Lim, and N. Saylani, "Internet banking adoption: comparing developed and developing countries," Journal of Computer Information Systems, vol. 51, pp. 52-61, 2010.

[14] P. Staszkiewicz, I. Chomiak-Orsa, and I. Staszkiewicz, "Dynamics of the COVID-19 contagion and mortality: country factors, social media, and market response evidence from a global panel analysis," IEEE Access, vol. 8, pp. 106009-106022, 2020.

[15] A. Strzelecki and M. Rizun, "Infodemiological study using Google trends on coronavirus epidemic in Wuhan, China," International Journal of Online and Biomedical Engineering, vol. 16, no. 4, pp. 139-146, 2020.

[16] F. Raciborski, J. Pinkas, M. Jankowski et al., "Dynamics of COVID-19 outbreak in Poland: a epidemiological analysis of the first two months of the epidemic," Polish Archives of Internal Medicine, 2020.

[17] J. M. Heines, "Evaluating the effect of a course web site on student performance," Journal of Computing in Higher Education, vol. 12, no. 1, pp. 57-83, 2000.

[18] R. Howard, L. Restrepo, and C.-Y. Chang, "Addressing individual perceptions: an application of the unified theory of acceptance and use of technology to building information modelling," International Journal of Project Management, vol. 35, no. 2, pp. 107-120, 2017.

[19] S. Abbasi, T. Ayoob, A. Malik, and S. I. Memon, "Perceptions of students regarding E-learning during Covid-19 at a private medical college," Pakistan Journal of Medical Sciences, vol. 36, p. S57, 2020.
[20] R. Spears, "Social influence and group identity," Annual Review of Psychology, vol. 72, 2020.

[21] Y. J. Joo, S. Park, and E. Lim, "Factors influencing preservice teachers' intention to use technology: TPACK, teacher selfefficacy, and technology acceptance model," Journal of Research on Technology in Education, vol. 21, pp. 48-59, 2018.

[22] J. F. Hair, J. J. Risher, M. Sarstedt, and C. M. Ringle, "When to use and how to report the results of PLS-SEM," European Business Review, pp. 164-182, 2019.

[23] H. W. Willaby, D. S. J. Costa, B. D. Burns, C. MacCann, and R. D. Roberts, "Testing complex models with small sample sizes: a historical overview and empirical demonstration of what Partial Least Squares (PLS) can offer differential psychology," Personality and Individual Differences, vol. 84, pp. 73-78, 2015.

[24] B. A. Nahla Aljojo, "Investigating effort expectancy and facilitating conditions affecting behavioral intention to use mobile learning," Journal of Southwest Jiao Tong University, vol. 55, 2020.

[25] A. Tarhini, K. A. Al-Busaidi, A. B. Mohammed, and M. Maqableh, "Factors influencing students' adoption of e-learning: a structural equation modeling approach," Journal of International Education in Business, vol. 10, no. 2, 2017.

[26] P. Isaias, F. Reis, C. Coutinho, and J. A. Lencastre, "Empathic technologies for distance/mobile learning," Interactive Technology and Smart Education, vol. 14, no. 2, 2017.

[27] L. Sedlock, "Price vs. cost of distance education enrollment," Annual Journal, vol. 163, 2018.

[28] T. M. Abbas, "Human factors affecting university hospitality and tourism students' intention to use e-learning: a comparative study between Egypt and the UK," Journal of Human Resources in Hospitality \& Tourism, vol. 16, no. 4, pp. 349-366, 2017.

[29] P. A. Radhakrishnan, "An empirical study on the effect of institutional factor on perceived value of E-learning in management education with specific reference to Es-qual," The Online Journal of Distance Education and e-Learning, vol. 6, p. 9, 2018.

[30] U. Sekaran and R. Bougie, Research Methods for Business: A Skill Building Approach, John Wiley \& Sons, Hoboken, NJ, USA, 2016.

[31] J. F. Hair, G. T. M. Hult, C. M. Ringle, and M. Sarstedt, A Primer on Partial Least Squares Structural Equation Modeling (PLS-SEM), Sage, Thousand Oaks, CA, USA, 2nd edition, 2017.

[32] P. Photopoulos, C. Tsonos, I. Stavrakas, and D. Triantis, "Acceptance of distance learning during the COVID-19 movement restrictions: does the year of studies matter?" in Proceedings of the 13th International Conference on Computer Supported Education (CSEDU 2021), vol. 1, pp. 591-602.

[33] A. R. Alsoud and A. A. Harasis, "The impact of COVID-19 pandemic on student's E-learning experience in Jordan," Journal of Theoretical and Applied Electronic Commerce Research, vol. 16, no. 5, pp. 1404-1414, 2021.

[34] F. Hassan, M. K. Amin, T. Khan, M. M. Emon, and A. Amin, "Roles of social influence in expediting online learning acceptance: a preliminary study on Bangladeshi learners," in Proceedings of the International Conference on Computing Advancements, pp. 1-6, New York, NY, USA, December 2020. 